\title{
Ecological connectivity in fragmented agricultural landscapes and the importance of scattered trees and small patches
}

\author{
Darrel Chin Fung Tiang ${ }^{1 *}$ (D), Andrew Morris ${ }^{2}$, Mathew Bell ${ }^{2}$, Christopher N. Gibbins ${ }^{1}$, Badrul Azhar $^{3}$ and
} Alex M. Lechner ${ }^{4,1}$

\begin{abstract}
Background: Fragmentation and habitat loss can restrict species movement and reduce connectivity, negatively impacting biodiversity. Characterising the overall connectivity of an area can inform better management of human modified landscapes. Contemporary connectivity modelling methods seldom incorporate fine-scale movement patterns associated with movement between fine-scaled structural connectivity elements such as scattered trees, roadside corridors and small patches of habitat. This study aims to characterise connectivity within the Karuah-Myall catchments, a typical woodland ecosystem that is fragmented by agriculture, using least-cost path analysis and a graph-theoretic approach; it focuses on how fine-scaled vegetation such as scattered trees support connectivity. We mapped scattered (and paddock) trees within this agricultural landscape where the main human modified land use was pasture. We modelled connectivity for a general representative woodland species using an interpatch dispersal distance and gap crossing threshold, and resistance from different land cover types. The gap crossing distance threshold was used to model movement between fine-scaled vegetation features. We compared the least-cost paths modelled with and without scattered trees.

Results: Our results show that by excluding scattered trees, least-cost paths across the cleared pasture landscape did not reflect the types of movement patterns typically observed from field studies, such as those associated with a foray-search strategy used by small and medium mammals and birds. The modelling also shows that the KaruahMyall catchments are well connected and provide value to biodiversity beyond the catchment borders, by connecting coastal vegetation to the Great Eastern Ranges national wildlife corridor initiative.
\end{abstract}

Conclusion: Connectivity models that exclude fine-scale landscape features such as scattered trees and small, linear patches risk misrepresenting connectivity patterns. Models of regional-scale connectivity can be influenced by the presence or absence of even the smallest features, such as scattered trees.

Keywords: Scattered trees, Landscape connectivity, Gap crossing, Fragmentation, Agricultural landscape

\footnotetext{
* Correspondence: khgzdtc@nottingham.edu.my

'School of Environmental and Geographical Sciences, University of

Nottingham Malaysia, Jalan Broga, 43500 Semenyih, Selangor, Malaysia

Full list of author information is available at the end of the article
}

\section{Springer Open}

( ) The Author(s). 2021 Open Access This article is licensed under a Creative Commons Attribution 4.0 International License, which permits use, sharing, adaptation, distribution and reproduction in any medium or format, as long as you give appropriate credit to the original author(s) and the source, provide a link to the Creative Commons licence, and indicate if changes were made. The images or other third party material in this article are included in the article's Creative Commons licence, unless indicated otherwise in a credit line to the material. If material is not included in the article's Creative Commons licence and your intended use is not permitted by statutory regulation or exceeds the permitted use, you will need to obtain permission directly from the copyright holder. To view a copy of this licence, visit http://creativecommons.org/licenses/by/4.0/. 


\section{Introduction}

Conversion of natural ecosystems for human land uses leads to fragmentation, loss of habitats and restriction of species movement (Lumsden and Bennett 2005; Lindsay et al. 2008; Hadley and Betts 2009; Beier et al. 2011; Rogan and Lacher Jr. 2018; Liu et al. 2020; Bolliger and Silbernagel 2020). The decrease in habitat connectivity has adverse effects on population viability, resulting in greater extinction risk than from the loss of habitat alone (Caughley 1994; Fischer and Lindenmayer 2006; Brook et al. 2008). Better management of human-modified landscapes is central to minimising the impact of fragmentation on species movement and connectivity and ultimately, ensuring the viability of populations and ecosystems.

Contemporary methods for modelling landscape connectivity include least-cost path analysis and graph theory; these provide a diverse toolbox for studying the different aspects of connectivity (Urban and Keitt 2001; Adriaensen et al. 2003; McRae et al. 2008; Foltête et al. 2012). Least-cost path analysis characterises nonhabitat/matrix based on dispersal costs, which represent the metabolic price and mortality risk of moving across such areas (Adriaensen et al. 2003; Sawyer et al. 2011). Dispersal cost is influenced by a combination of land cover attributes, such as urbanisation, and speciesspecific dispersal probabilities over various distances. Cost-weighted analysis is used to produce the least-cost pathways connecting suitable habitat patches. Subsequently, using a graph theoretic approach, network measures are calculated to quantitatively assess the significance of patches within a connectivity network (Minor and Urban 2008; Rayfield et al. 2011).

Many studies have incorporated these approaches in modelling landscape connectivity and have made significant contributions to a now large body of research (Urban and Keitt 2001; Adriaensen et al. 2003; McRae et al. 2008; Urban et al. 2009; Rayfield et al. 2011; Foltête et al. 2012). However, these approaches have a number of important limitations; most notably, they do not adequately incorporate truly fine-scale features such as scattered trees (including paddock trees) and road-side vegetation patches, nor address how these facilitate movement between larger habitat patches (Lechner et al. 2015b). In landscapes fragmentated by pasture, scattered trees, small patches and corridors are recognised as important facilitators of movement (Fischer and Lindenmayer 2002; van der Ree et al. 2004) as they allow for species to move long distances from one patch to another by acting as stepping stones.

Scattered trees are dispersed individual trees, often remnants of intact forest, that are surrounded by open space (Manning et al. 2006). They are common in human dominated and fragmented forest landscapes and can result from practices such as clearance and thinning of forests (Manning et al. 2009). They are recognized for their usefulness and are widely regarded as "keystone structures" in human-dominated landscapes: they provide foraging sites and shelter for many species (Carruthers et al. 2004; Le Roux et al. 2018; Barth et al. 2020), habitat for insectivores and pollinators (Lumsden and Bennett 2005; Prevedello et al. 2018), focal points for tree regeneration (Dorrough and Moxham 2005; Derroire et al. 2016), soil nutrient retention (Wilson 2008) and connectivity for a wide range of biota (Manning et al. 2006). In addition, they act as a stopover and a place to rest, providing protection from predation for many woodland and forest species on their ventures out into the open matrix, effectively making fragmented landscapes "usable".

The aim of this study was to characterise connectivity in fragmented agricultural landscapes dominated by open pastures, where we hypothesised that dispersal is facilitated by scattered trees and small patches of vegetation such as road-side corridors. We assessed (1) how scattered trees and other fine-scaled structural connectivity elements influence connectivity patterns within fragmented landscapes and (2) the contribution of such landscapes to regional-scale connectivity beyond their boundaries. To address the study aim, we used information on fine-scale dispersal behaviours to model the contribution of scattered trees and small patches for the Karuah-Myall catchments, New South Wales, Australia, for a "general representative species" dependent on native woody vegetation (Lechner et al. 2015b). The Karuah-Myall catchments represent a typical woodland ecosystem on the east coast of Australia which has been fragmented by pasture agriculture. We mapped and modelled connectivity using an interpatch dispersal distance, gap crossing threshold and resistance from different land cover types. The gap crossing distance threshold was used to model movement between fine-scaled vegetation features. Movement was characterised with least-cost paths, and the importance of links and patches to connectivity was quantified using a graph theoretic approach (Foltête et al. 2012). We compared the least-cost paths modelled with and without scattered trees. In addition, the importance of protected areas for conserving connectivity and the contribution of the study area to connectivity beyond its boundaries, specifically the Great Eastern Ranges national wildlife corridor scheme was also assessed. We conclude by discussing the important role of scattered trees and small patches in connecting landscapes and the importance of explicitly modelling them.

\section{Methods}

Study area

The Karuah River catchment is situated in the lower north coast of New South Wales, Australia. It borders the Hunter River catchment in the south, and the Manning 
River catchment in the north. The catchment is approximately $2410 \mathrm{~km}^{2}$. Land uses within the Karuah River catchment include state forests, agricultural land, national parks, coal mining and urbanised areas. The catchment is typified by narrow valleys to the north that widen to the mid and lower regions. The catchment is valued for its rich biodiversity and diverse landforms (Great Lakes Council 2014). Adjacent to the Karuah River catchment, the Myall Lakes catchment has an area of more than 400 $\mathrm{km}^{2}$. The Myall River is the major tributary of this catchment, with its headwaters extending to Craven Nature Reserve and the Kyle Range. Land use within the Myall Lakes catchment ranges from agricultural, with livestock farming being most popular, to forestry and protected areas on steeper slopes and small urban and peri-urban areas such as the townships of Bulahdelah, as well as the popular tourist destinations of the Tea Gardens-Hawks Nest area. Much of the native woodland cover within the two catchments remains intact. Cleared areas exist in the valleys to the north and east and towards the coast in the south of the two catchments. Here, native trees remain as scattered or paddock trees standing above managed pastures of native grass (Great Lakes Council 2015). Scattered tree species common within the catchments include eucalypts such as Tallowwood, and several species of Gum and Mahogany trees. Several Angophora spp. and Corymbia spp. are also common, such as the Smooth and Roughbarked Apple, and Bloodwood and Spotted Gum, respectively (MidCoast Council 2018).

\section{Modelling fine-scale connectivity}

This study follows a framework described by Lechner et al. (2015a, b) to characterise connectivity based on fine-scale dispersal behaviour (Fig. 1). The framework has the following workflow:

i. Identification of key ecological connectivity parameters

ii. Pre-processing spatial data based on these parameters

iii. Inputting spatial data to existing connectivity modelling software

This study modelled generic connectivity between environmentally similar habitats instead of a particular species, comparable to the land-facet approach that has been applied in Australia (Lechner et al. 2015a, b, c) and internationally (e.g. Brost and Beier 2012). A modelling approach such as this is a balance between the complexity of parameterising and interpreting a multi-species connectivity model, and the simplicity of a structural connectivity model that ignores the inter-species

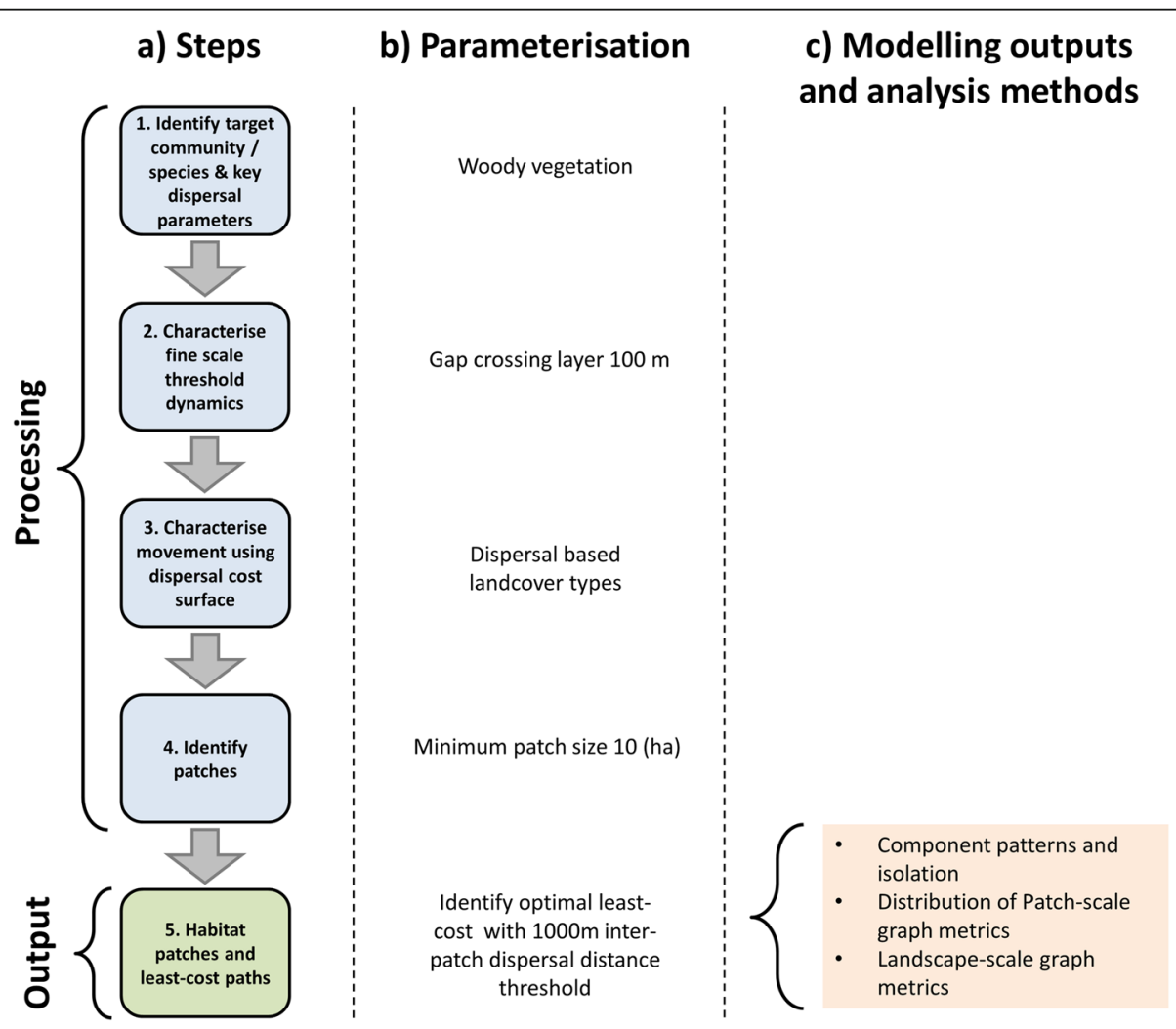

Fig. 1 Flow diagram describing the workflow of connectivity assessment of the Karuah-Myall catchments 
complexity of movement between patches (Lechner et al. 2015b). This approach is based on a "general representative species" which considers native woody vegetation as habitat; it has been applied previously to similar woodland dominated landscapes in Australia (Lechner et al. 2015b, c). Such patches are habitat for the majority of the native fauna in the region affected by fragmentation, as well as floral species that rely on them for dispersal (Lechner et al. 2015b).

\section{Identification of key ecological connectivity parameters}

The model was parameterised using dispersal values from a systematic review by Doerr et al. (2014). This review assessed how structural connectivity facilitates dispersal and synthesised average values for gap-crossing distance and interpatch dispersal distance thresholds from 80 studies from 98 sources. These values were relevant to the present study as most of the reviewed studies have similar ecosystems and are also impacted by fragmentation from agriculture. The connectivity parameters were:

i. $1000 \mathrm{~m}$ interpatch dispersal distance

ii. $100 \mathrm{~m}$ gap-crossing distance

iii. 10 ha minimum habitat patch size

\section{Pre-processing spatial data based on these parameters}

Along with these ecological parameters, three spatial inputs were used: a habitat patch layer, a dispersal cost surface based on land use mapping and a gap crossing layer based on the gap crossing distance threshold.

Creation of habitat map and land use resistance surface Land use and land cover maps were provided by MidCoast Council (2018), New South Wales, Australia. A general land use map and two vegetation land cover maps were used to derive the necessary spatial inputs.
We manually edited the spatial data to prepare for the modelling process as the original data were considered inadequate for modelling fine-scale connectivity; this editing is detailed below. The final habitat map is made up of combined native woody vegetation features, whereas the dispersal cost map was a composite of broad land cover classes (Table 1) which includes native vegetation and the gap crossing surface. All data processing was performed using ArcGIS software (ESRI 2018).

The primary land cover datasets provided by MidCoast Council had three different representations of the distribution of land cover in the study area. These datasets were:

i. MidCoast Council compiled fine-scale vegetation community map

ii. Mid North Coast forest ecosystem distribution map

iii. Great Lakes Council native vegetation distribution map

The layers were overlaid and manually corrected while referring to an ArcGIS base map (ESRI 2018). The goal was to produce a harmonised vegetation layer by combining the most accurate components of three primary datasets. This resulted in a composite vegetation layer that was spatially complete and correct for the year 2016.

Roads and waterways were merged with both the habitat and land cover maps to provide a better representation of vegetation and land use patterns which potentially impact fine-scale movement. For example, by adding roads, we were able to identify discontinuities in vegetation patches which were originally mapped as a single patch. We used Open Street Map (OSM) data to identify roads, streams and rivers that were missing from the existing datasets. The following edits were made to the data from OSM:

Table 1 Description of original land use zones, conversion to broad resistance classes and resistance values. Note the original land use layer was updated manually and with Open Street Map data as described in the text

\begin{tabular}{|c|c|c|c|c|}
\hline Original land use & $\begin{array}{l}\text { General } \\
\text { class }\end{array}$ & $\begin{array}{l}\text { Resistance } \\
\text { class }\end{array}$ & $\begin{array}{l}\text { Resistance } \\
\text { percentage }\end{array}$ & $\begin{array}{l}\text { Resistance } \\
\text { pixel value }\end{array}$ \\
\hline $\begin{array}{l}\text { Sclerophyll shrubland, sclerophyll forest, coastal dry forest, coastal headland, woodland, } \\
\text { dry heathland, wet heathland, mangrove woodland, dry rainforest, riparian forest, tall } \\
\text { shrubland. }\end{array}$ & Habitat & Other & $100 \%$ & 5 \\
\hline sand complex, grassland, sedgeland, rushland, freshwater meadow mix. & Non-habitat & Other & $100 \%$ & 5 \\
\hline $\begin{array}{l}\text { cleared, golf courses, parkland, parkland/grassland, residual pine forest, cleared pasture, } \\
\text { managed pine plantation, rock, sand, cleared grassland. }\end{array}$ & Other & Other & $100 \%$ & 5 \\
\hline $\begin{array}{l}\text { urban or residential development, quarry, mining strip, industrial land, landfills, schools, } \\
\text { mines-coal, fences. }\end{array}$ & Infrastructure & Infrastructure & $200 \%$ & 10 \\
\hline $\begin{array}{l}\text { bridleway, construction road, motorway, motorway link, rail, residential road, rest areas, } \\
\text { secondary roads, service roads, tertiary roads, tertiary link, tracks. }\end{array}$ & Roads & Roads & $200 \%$ & 10 \\
\hline water, river, stream & Water & Hydro & $300 \%$ & 15 \\
\hline
\end{tabular}


i. Filter out small roads and tracks if they did not show up on Google Earth/Google Maps. These were dirt roads or abandoned roads that had little to no traffic and thus do not affect movement.

ii. Buffer the roads and waterways to a total width of $7.5 \mathrm{~m}$. This ensures that the roads were wide enough to show up as continuous strips with no breaks.

iii. Combine roads with habitat map and the subsequent land use map.

To finalise the habitat map, we manually digitised missing vegetation areas large enough to be considered as a patch ( $\geq 10 \mathrm{ha})$.

Resistance to dispersal can be described as how movement costs associated with different land cover reduces the maximum distance individuals can travel. For instance, a land cover which doubles dispersal cost would reduce the interpatch dispersal distance threshold of 1 $\mathrm{km}$ to $500 \mathrm{~m}$. This study follows the same dispersal costs assigned to each pixel as in Lechner and Lefroy (2014).

To produce a land use resistance map, the classes from the original data sets were categorised into broader classes based on the general ways in which land cover affects movement (Table 1). Dispersal costs varied from no cost (habitat and non-habitat) to water which reduced distance by $300 \%$. General classes were further grouped into resistance classes and given a resistance pixel value that represents the cost of movement. Resistance pixel values used are multiples 5, which is the pixel size of all spatial data used in this study. A resistance value of 5 will have no cost to movement and pixels with a resistance value of 10 will have twice the resistance and 15 with three times the resistance.

Gap-crossing layer The gap-crossing layer identifies distances between structural connectivity elements and patches beyond the gap-crossing distance threshold. Areas beyond this threshold act as barriers to dispersal and vegetated areas smaller than the minimum patch size are considered as structural connectivity elements. In addition, we manually digitised 14,125 trees (points) and 6703 groups of trees (polygons) which were not included in the original land cover maps. These were trees within cleared or pastural land. A final land cover map consisting of the land cover classes and scattered trees was produced that depicts general land cover classes found within the study area (Table 1). The gap crossing layer was created by combining the additional trees with the habitat map and applying a buffer of half the gapcrossing distance threshold $(50 \mathrm{~m})$ to all vegetation. Areas outside the buffer distance are considered as barriers to movement. If connectivity elements are present within the gap-crossing distance, the buffers will meet or overlap, allowing for movement. Dispersal will not happen outside the buffered areas.

Dispersal resistance layer The dispersal resistance surface describes how land cover between patches restricts movement. It is produced by combining the land use map and the gap crossing layer. The gap-crossing layer takes priority over other land cover classes. The resulting dispersal cost layer is one that acknowledges finescale threshold dynamics as it ensures dispersal is impossible where gaps are greater than the gap-crossing distance. The layer also allows for modelling of cumulative costs, where dispersal is possible but may be impeded by land use.

\section{Connectivity modelling}

A graph theoretic approach along with least-cost paths was used to assess connectivity across the two catchments. Using a graph theoretic approach, we were able to characterise the landscape as a network of patches connected by links, described by least-cost paths (Minor and Urban 2008; Dale and Fortin 2010). We modelled connectivity using Graphab 2.2 software (Foltête et al. 2012). The outputs from the connectivity model were interpreted by visualising fragmentation and least-cost paths and quantifying the importance of patches and linkages using graph metrics (Fig. 2).

In the first stage of analysis, we identified patches or groups of interconnected patches that are isolated from other patches, known as "components". Their boundaries are identified by Graphab, at the midpoint between patches from different components, and are used for visualisation purposes only (see Fig. 3). Spatial patterns of these components are useful for characterising fragmentation and barriers to connectivity at the regional scale (Lechner et al. 2015c). Large components describe multiple patches that are connected, and help with the characterisation of how regions are connected. Numerous small components represented by a single or several small patches describe regions where dispersal is highly constrained.

At the next stage, graph metrics were used to assess the significance of patches and links within the connectivity network. We calculated two patch scale graph metrics to characterise the importance of patches and linkages for contributing to dispersal. These were the delta integral index of connectivity (dIIC) (Pascual-Hortal and Saura 2006; Saura and Pascual-Hortal 2007) and clustering coefficient (CC) (Ricotta et al. 2000; Minor and Urban 2008). dIIC describes the impact of the loss of habitat availability caused by the removal of the focal patch relative to the connectivity network. The higher the value, the higher the connectivity. CC measures path redundancy between the patch and its neighbouring 


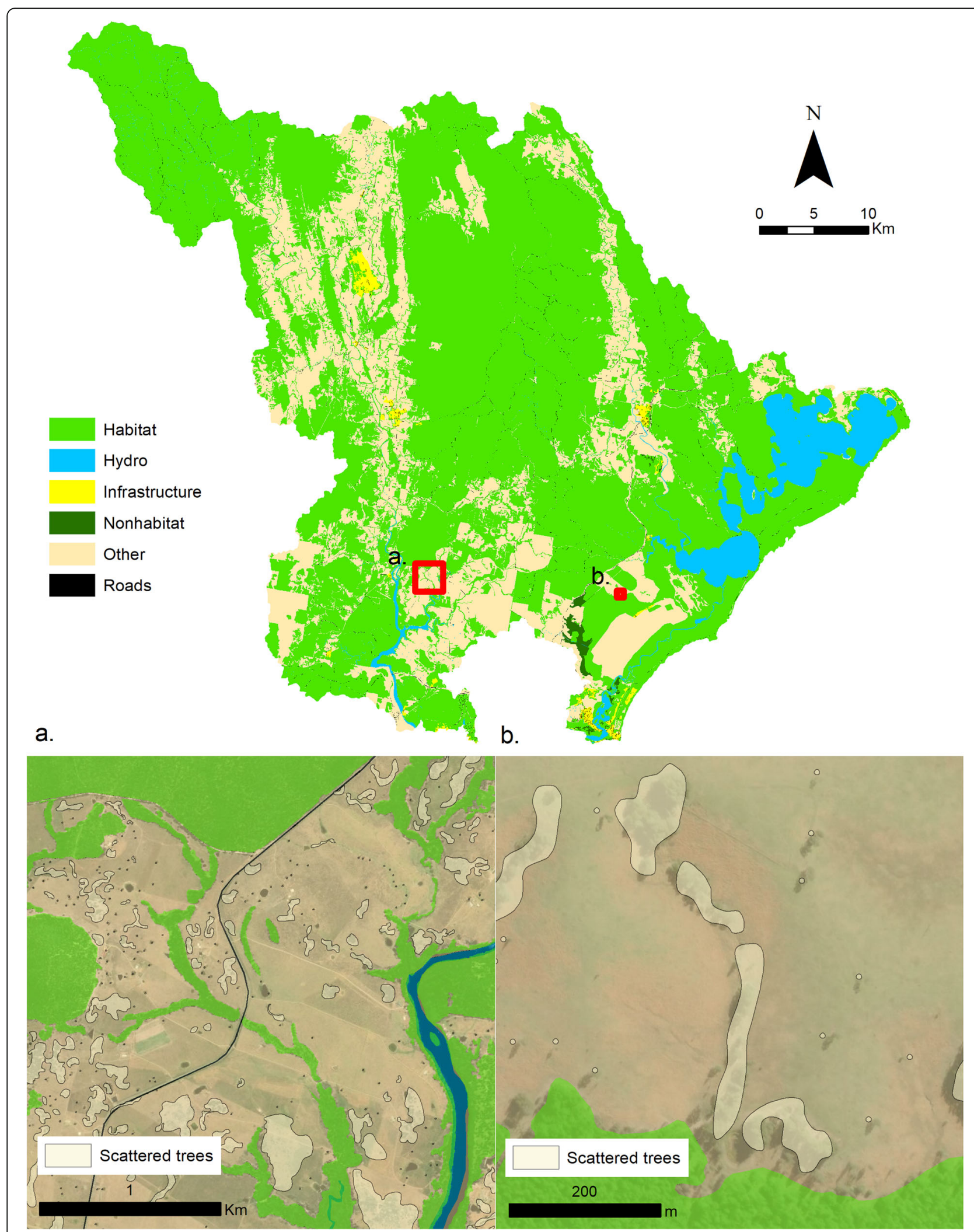

Fig. 2 Land cover map depicting general land cover classes (Table 1) and scattered trees. Individual scattered trees are shown as points and grouped scattered trees as polygons in insets $\mathbf{a}, \mathbf{b}$ 
patches. A higher coefficient means alternative pathways exist for linking neighbouring patches. This is visualised by Graphab as nodes and links across a network.

We assessed the contribution of scattered trees to finescale connectivity by modelling connectivity within the study area for two scenarios. The default scenario uses a dispersal cost map that obeys gap crossing distance thresholds through the gap crossing layer, which includes structural connectivity elements such as scattered trees. In the second scenario, we modelled connectivity with a dispersal cost map that is not limited to movement beyond the gap crossing distance threshold. By comparing the two scenarios, we were able to highlight the contribution of small patches and scattered trees to fine-scale connectivity; more specifically, a comparison focused on relative movement patterns of leastcost paths, and the distribution of component boundaries, nodes and links across the landscape can be made.

Finally, we tested the sensitivity of the model to dispersal costs and patch size at the landscape-scale using graph metrics. We repeated the modelling and analyses with another scenario that used only the habitat map without dispersal costs. This allowed for the identification of key dispersal distances for connecting the catchment. It also functioned as a sensitivity analysis, characterising how the interpatch dispersal distance effected the results of the analysis. We also modelled the default scenario with varying minimum patch sizes, ranging from 1 to 30 ha, to determine the influence of patch size on the results. In addition, patch size may decrease or increase the probability of accurately mapping and extracting these patches (Lechner et al. 2009). For each scenario, we calculated the landscape-scale metrics, number of components (NC) and the integral index of connectivity (IIC), to assess overall differences in connectivity patterns. The IIC calculates the probability of two randomly placed dispersers accessing each other (Pascual-Hortal and Saura 2006) and NC is a simple measure of the number of isolated patches in the landscape (Urban and Keitt 2001).

\section{Connectivity network protection status and contribution to Great Eastern Ranges}

To assess how important existing national parks, forest reserves and other protected areas are for connecting

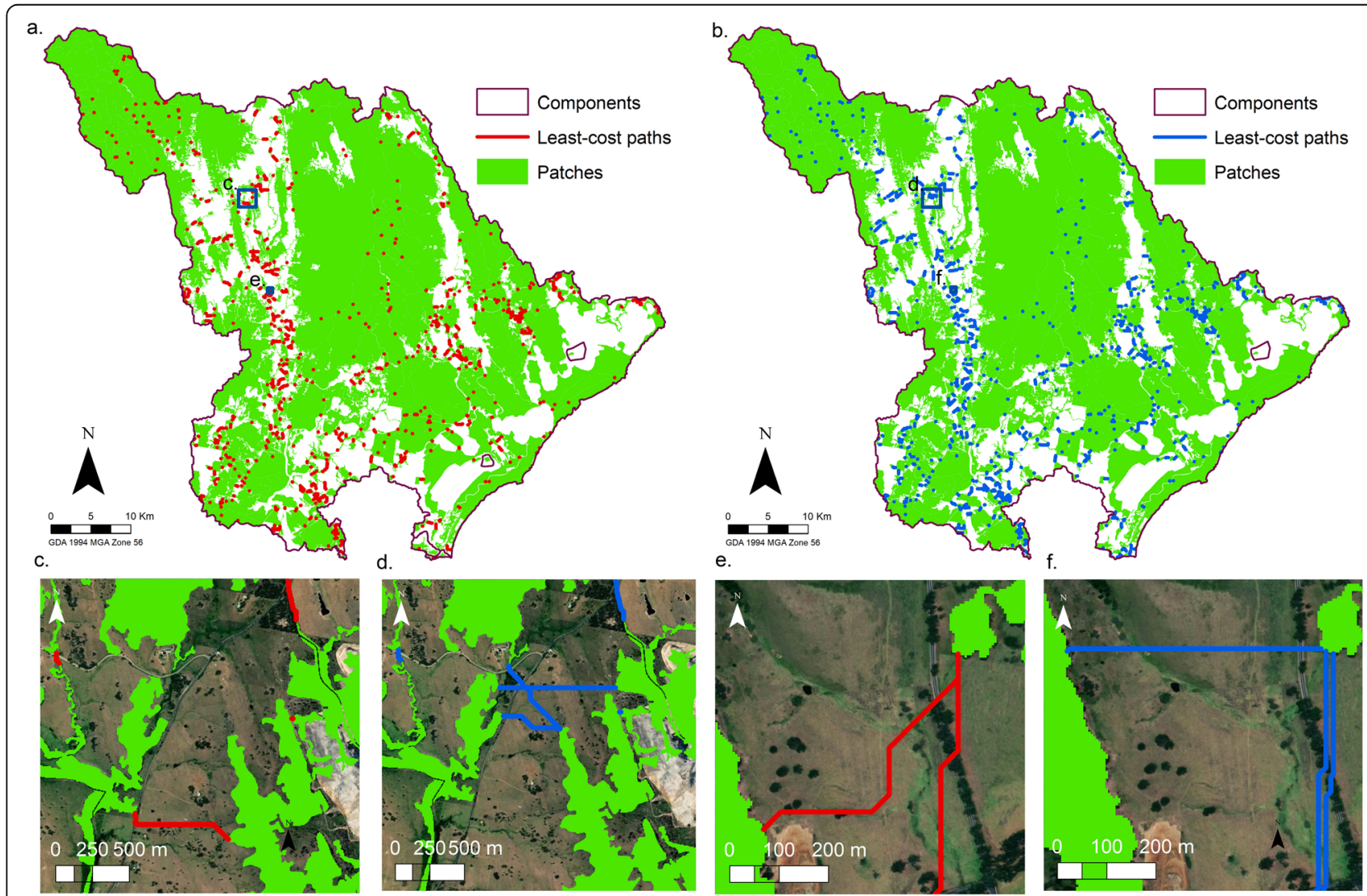

Fig. 3 Habitat patches, least-cost paths, and component boundaries of the Karuah-Myall catchments: a, c, e with the gap crossing layer characterising movement between scattered trees and $\mathbf{b}, \mathbf{d}$, $\mathbf{f}$ without the gap crossing layer. $\mathbf{c}-\mathbf{f}$ Insets showing the characteristics of the least-cost paths 
patches, we overlaid the connectivity modelling outputs with protected area spatial data. A single protected area spatial dataset was produced, consisting of the following classes: National Parks, Forest Reserves, Coastal Wetland, Environmental Conservation, Environmental Management, Flora Reserve, Forestry, Protected Area, State Conservation Area and State Forest. We then identified whether patches and links which had no protection status were important for connectivity within the study area.

We also assessed visually how the Karuah-Myall catchments contribute to connectivity across the Great Eastern Ranges (GER), a national scale regional planning and connectivity initiative centred on the Great Dividing Range and the Great Escarpment. The GER spans the Grampians, Western Victoria and Far North Queensland (https://www.ger.org.au), and crosses the Karuah River catchment to the west.

\section{Results}

\section{Least-cost paths and components}

A visual assessment of Fig. 3a shows that the KaruahMyall catchments are generally well connected: almost all habitat patches within the landscape are linked to each other, except for four isolated patches in the southeast, as denoted by the component boundaries. These components are visualised in Fig. 3a as patches surrounded by purple lines. The occurrence of least-cost paths between patches (red lines) indicates that the cumulative cost-weighted distance between patches was less than $1000 \mathrm{~m}$ and also that the gap-crossing distance between structural connectivity elements was less than $100 \mathrm{~m}$. Examples of the least-cost paths are shown by the insets. Least-cost paths avoid high resistance land covers such as settlements.

\section{Patch-scale graph metric-delta integral index of connectivity}

The dIIC highlights patches based on their potential to facilitate dispersal and their total area, as well as important linkages (Fig. 4). Figure 4a shows a uniformly distributed network of patches with disproportionately higher dIIC values, due to their contribution to connectivity within the landscape. A distinct spine of high dIIC value patches and linkages extends from the north to the south-east and then to the south. This spline branches into two at the central region where one branch continues south-west and the other south-east. These are mostly large sized patches, with the high dIIC linkages between them being critical for connecting the catchments.

\section{Importance of scattered trees and small patches}

We modelled connectivity for the same landscape without incorporating gap crossing layer (no scattered trees) to illustrate the impact of scattered trees on connectivity. Fig. 3b, Fig. 4b and Fig. 5b show the movement patterns and distribution of key nodes and linkages in a landscape where movement is allowed beyond the gap crossing threshold. Similar to Fig. 3a, Fig. 3b shows a generally well connected landscape; there is only one isolated patch in the south-east. The cluster of patches that was previously isolated in the southernmost tip in the east is now connected to its surrounding patches. Least-cost paths appear more frequently in this scenario (blue lines), and this is apparent in Fig. $3 \mathrm{~d}$ and $\mathrm{f}$. By

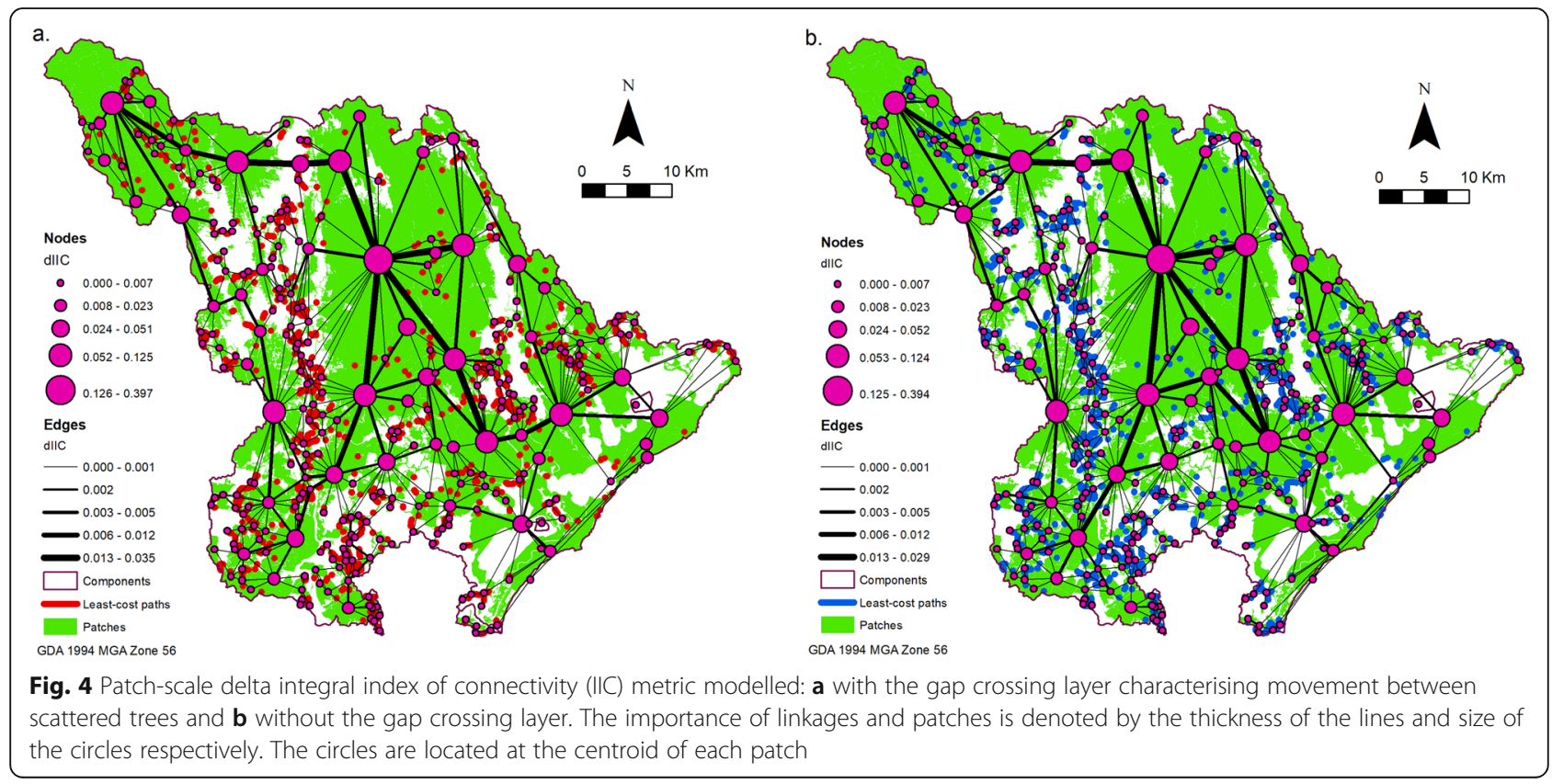



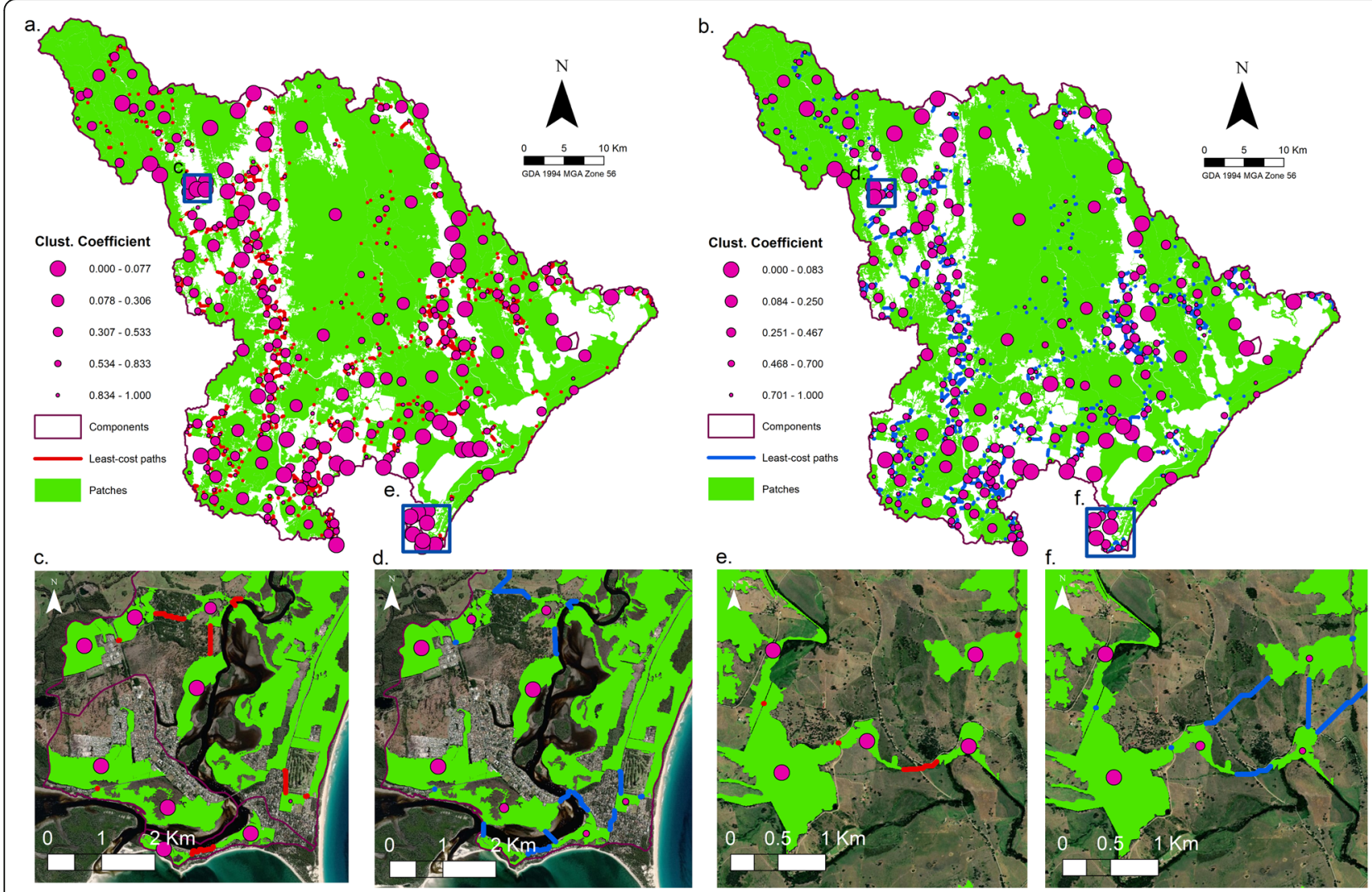

Fig. 5 Patch-scale metric, clustering coefficient (CC), characterises the level of redundancy (i.e. alternative routes) between neighbouring patches: $\mathbf{a}, \mathbf{c}, \mathbf{e}$ with the gap crossing layer characterising movement between scattered trees and $\mathbf{b}, \mathbf{d}$, $\mathbf{f}$ without the gap crossing layer. Large circles represent crucial patches for connectivity. $\mathbf{c}-\mathbf{f}$ Insets showing the characteristics of the least-cost paths

comparing Fig. $3 \mathrm{c}$ and d, we are able to visualise the effect of a gap crossing distance threshold on movement. Without the threshold, least-cost paths extend beyond $100 \mathrm{~m}$ between gaps, ignoring threshold dynamics and cumulative costs to movement. Fig. 3e shows how movement of the least-cost paths are sensible and utilises scattered trees as stepping stones to a nearby patch; this contrasts with Fig. 3f in which they are able to cross the open matrix while ignoring scattered trees.

Fig. 4b shows a similar distribution of dIIC values to the default scenario, where a uniformly distributed network of patches with disproportionately higher dIIC values exists. An almost identical spine of high dIIC value patches and linkages is also present here. The upper limit for dIIC for this scenario is lower than the default scenario.

The CC highlights patches with low redundancy and allows us to address the effect of paddock trees on the role of patches. A high $\mathrm{CC}$ value indicates that there are alternative pathways to reach neighbouring patches. The two scenarios are compared in Fig. 5. In Fig. 5a, there are many nodes with low CC values and many of these occur along the strips of cleared land in the west, south and east. Patches with low $\mathrm{CC}$ values indicate that they are crucial to connectivity as they provide a unique link to other patches. The same trend is seen in the scenario without the gap crossing layer (Fig. 5b), but with patches having generally higher $\mathrm{CC}$ values. Again, insets are included to clarify movement patterns. Fig. 5d, f shows that more patches are connected when the gap crossing threshold is not considered. The component boundary that exists in Fig. 5c is now gone in Fig. 5d. Without a threshold where movement can only occur if two scattered trees are close enough, least-cost paths appeared across a wide river with no stepping stone structures in between, to connect neighbouring patches. Fig. 5c, e shows that, when structural connectivity elements are considered, patches generally have a lower redundancy value compared to a scenario where they are ignored. Again, if scattered trees are ignored patches are connected to neighbours by multiple routes, increasing their redundancy (Fig. 5d and f).

\section{Sensitivity analysis}

Figure 6 shows that there was very little difference in global connectivity (i.e. at the regional scale) between 
the different choices in model parameterisation. This indicates that the greatest driver of connectivity within the Karuah-Myall catchments is interpatch dispersal distance, not resistance due to land cover. The sensitivity analysis also provides a coarse-scale assessment of connectivity for species with shorter and longer dispersal distances than the general representative species which was the focus of our study. There was a large decrease in NC and increase in IIC at the 50 to100 m distance threshold for all parameterizations, suggesting that species with these movement distances or less are most likely to be affected by fragmentation in the catchments. However, these species, which tend to be small sized, will have lower requirements for total patch area so are less likely to be impacted by fragmentation. Figure 6 also shows that scenarios with and without gap crossing are very similar. In Fig. 6a, there are only two components at the $1000 \mathrm{~m}$ threshold mark, whereas if paddock trees are considered, the number of components increases to five. Nevertheless, we did not expect a major difference between the default scenario and one without gap crossing. On a fine scale, movement patterns and patch redundancy can still be misrepresented if scattered trees are ignored, even when the two scenarios share similar qualities in the distribution of landscape scale metrics. Additionally, Fig. 6 shows that NC and IIC decrease and increase with minimum patch size respectively. Analyses with a minimum patch size of 1 ha would require datasets with a spatial resolution of $100 \times 100 \mathrm{~m}$ or finer which are provided by most conventional satellite used in land cover mapping, such as Landsat (30 m) and Sentinel $2(10 \mathrm{~m})$. This means that satellite spatial resolution is unlikely to impact the delineation of habitat patches (Lechner et al. 2009).

\section{Connectivity in protected areas and contribution to Great Eastern Ranges}

Figure 7 shows dIIC values and indicates that the majority of high dIIC nodes and linkages are within protected areas. The exception is a region to the north-west which has no protection status (Fig. 7a). This area includes high value patches and linkages in the north which connects west and east of the study area. Another key region without protection is in the south-west (Fig. 7b).

Figure 8 shows dIIC values and the overlap with the Great Eastern Ranges. There are few nodes and linkages with high dIIC values within the GER. There is one significant node to the north and one more just below the middle, in the west. These areas are important for connectivity.

Figure 9 shows the Karuah-Myall catchments in the context of the GER. Fig 9a shows the location of Karuah-Myall catchments in relation to the GER at the national scale. Figure $9 \mathrm{~b}$ shows visually that there is a cleared region between north and south (red arrow) forested areas in the GER to the west of the Karuah-Myall catchments. The yellow arrow in Fig. 9b represents a hypothetical potential linkage enabling movement from patches in the north to patches in the south of GER. The Karuah-Myall catchments is part of a region close to the east coast which potentially also provides another north to south linkage. In Fig. 9c, the arrows are used to visualise hypothetically how the Karuah-Myall catchments connect to the GER in the north-west, and the
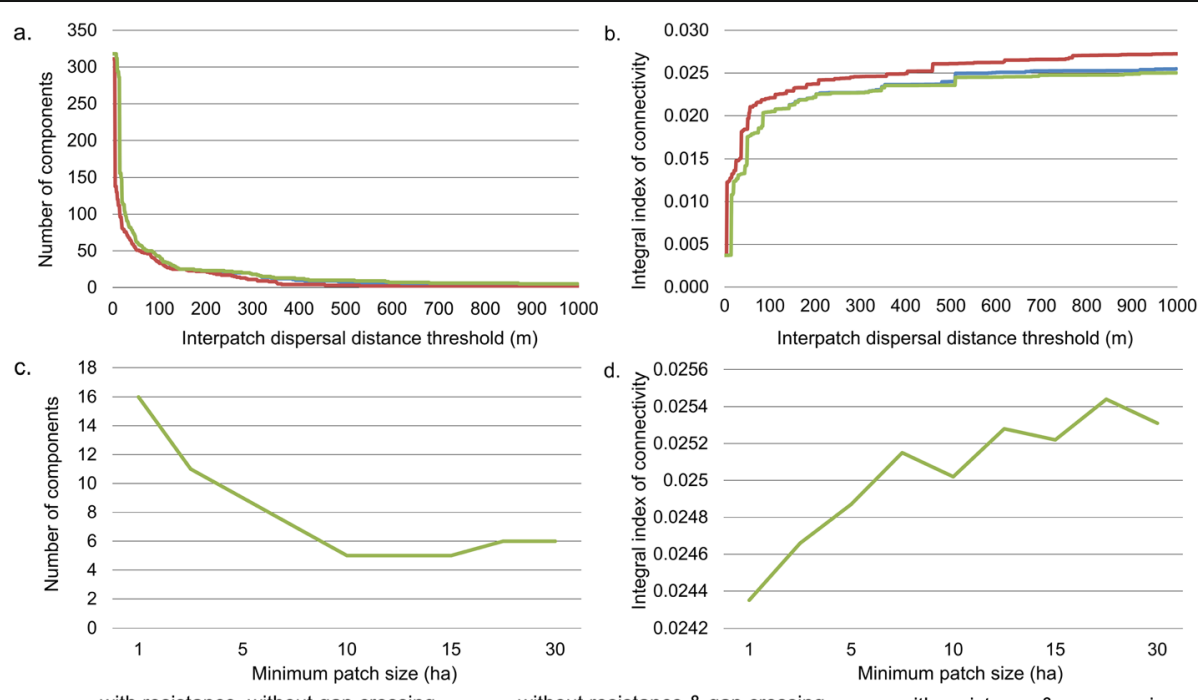

Fig. 6 Number of components and integral index of connectivity versus interpatch dispersal distance threshold $\mathbf{a}$, $\mathbf{b}$ and minimum patch size $\mathbf{c}$, $\mathbf{d}$ a $\mathbf{b} \mathbf{b}$ Compare model scenarios with resistance, without resistance and without the gap crossing layer, while $\mathbf{c}$, $\mathbf{d}$ connectivity shows that the metrics are negatively and positively correlated to minimum patch size respectively 


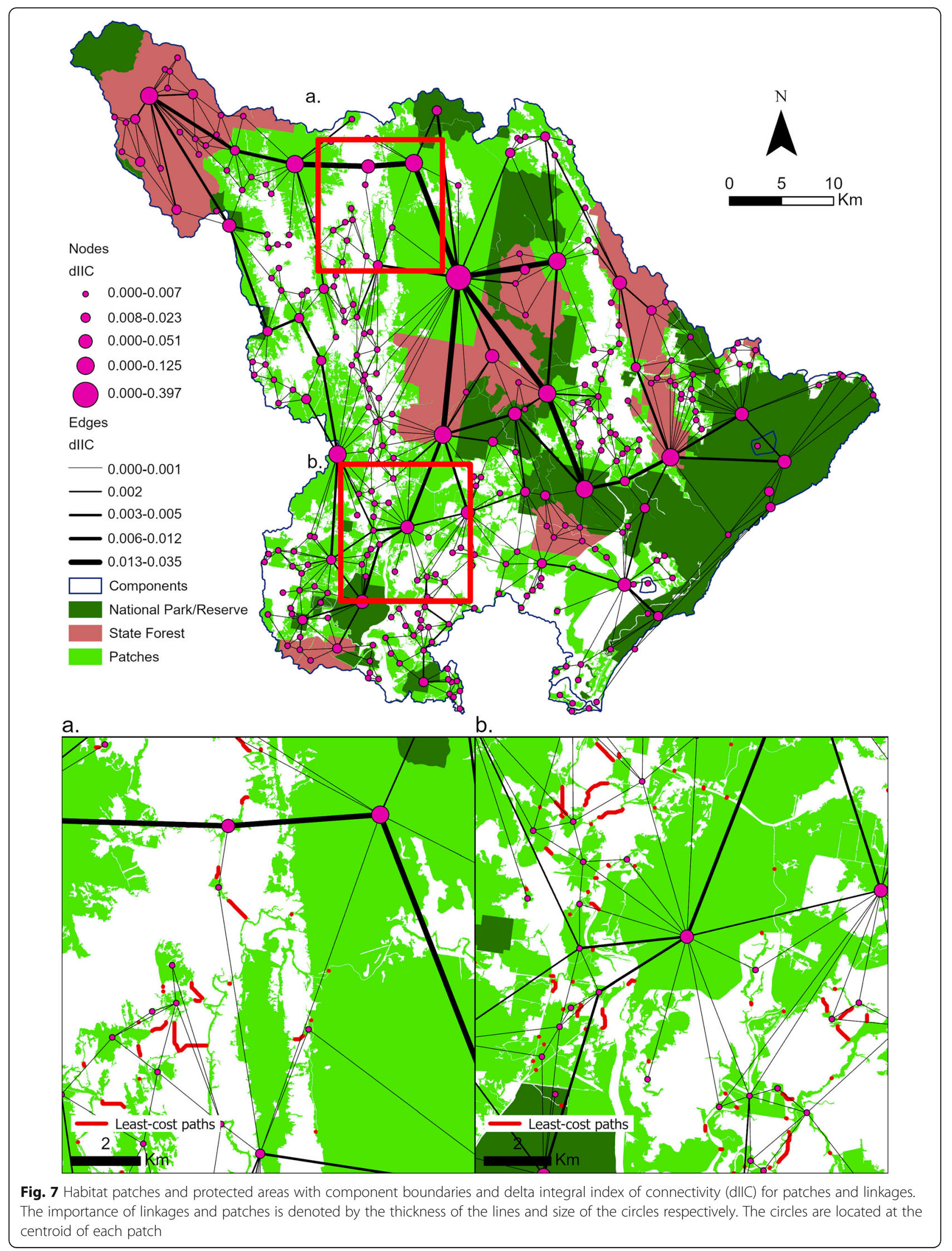




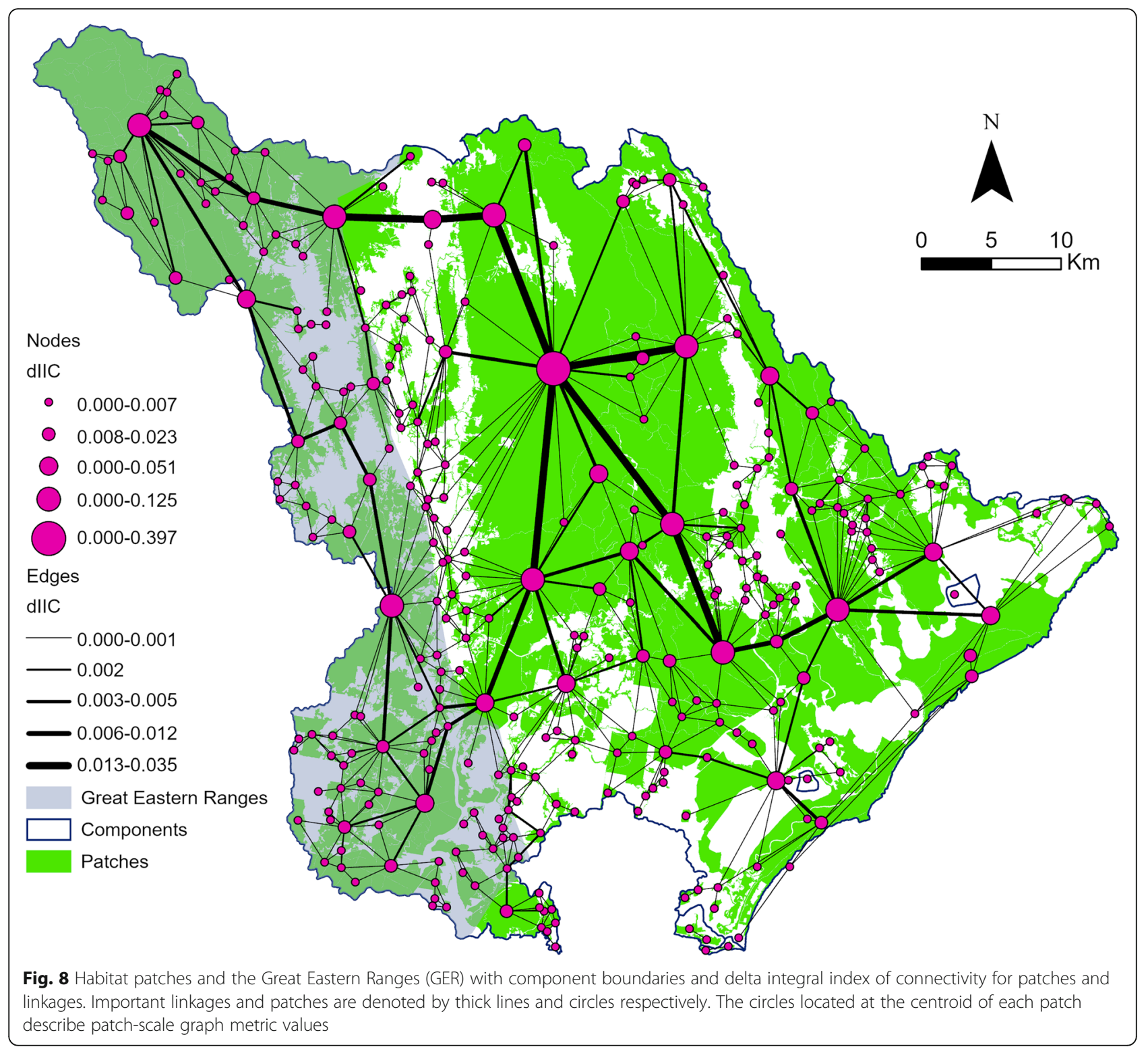

south-west, shown by the light blue and dark blue arrows respectively.

\section{Discussion}

\section{Overall connectivity}

Our study showed that the Karuah-Myall catchments are well connected, with only four isolated patches evident from the results of the analyses. The study area is fragmented by two agricultural regions along the valley floors. Although these areas have been cleared, they still support many scattered trees spaced below the gapcrossing threshold distance. The sensitivity analysis shows that species with an interpatch dispersal distance threshold of 50 to $100 \mathrm{~m}$ or less are likely to be mostly affected by fragmentation in the study area (Fig. 6). This study provided a coarse level general assessment of connectivity for the Karuah-Myall catchments. While we only used a "general representative species" for the parameterisation of the model, the sensitivity analysis suggests that it is likely that the catchments are well connected for most species that depend on woody vegetation. Further assessments for species of conservation concern which have more specific habitat requirements (e.g. utilise a subset of woody vegetation, or perhaps grasslands) and or have specific movement requirements not captured by our resistance model (i.e. roads are barriers to movement) are potentially required. 

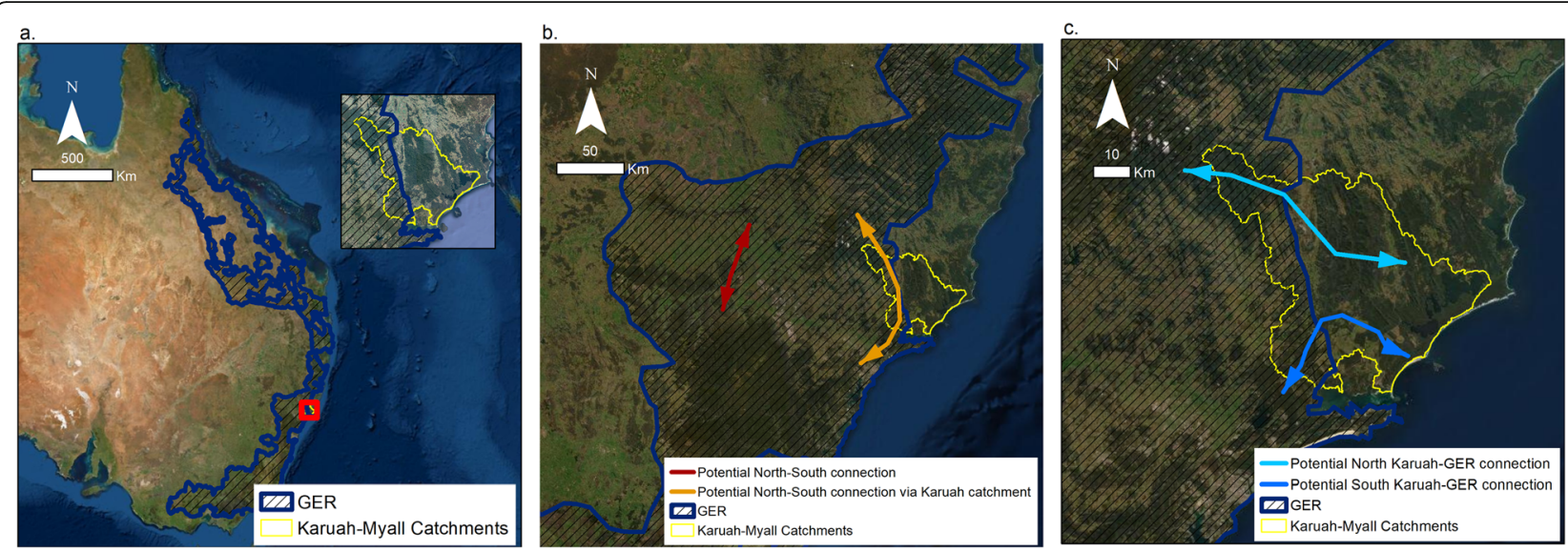

Fig. 9 a Extent of the Great Eastern Ranges and the location of the Karuah-Myall catchments. b Hypothetical North-South connection between the Karuah-Myall catchments and the GER. $\mathbf{c}$ Hypothetical pathways denoted by arrows showing how Karuah-Myall catchments supports movement between coastal patches within the study area and the GER

\section{Importance of scattered trees and small patches for representing fine scale dispersal patterns}

Many field-based studies have shown that gaps in discontinuous habitats limit movement across fragmented landscapes (Desrochers and Hannon 1997; Rail et al. 1997; Grubb and Doherty 1999; Bélisle and Desrochers 2002; Creegan and Osborne 2005). The presence of scattered trees and the distance between them can impact overall connectivity within fragmented landscapes, as many species avoid being exposed in the open matrix. For example, Squirrel Gliders (Petaurus norfolcensis) have been observed to glide between individual trees not more than $75 \mathrm{~m}$ apart (van der Ree et al. 2004) and forest birds such as the Grey-shrike Thrush (Colluricincla harmonica) and White-throated Treecreeper (Cormobates leucophaea) perceive cleared land as barriers to movement and gaps more than $100 \mathrm{~m}$ significantly reduce their functional connectivity (Robertson and Radford 2009).

Our study explicitly incorporates the ecology of fine-scale connectivity through mapping vegetation at a high spatial resolution by modelling a gap-crossing distance, building on previous work (Lechner and Lefroy 2014; Lechner et al. 2015b, c) specifically to address the role of scattered trees. This approach is especially important in pasture dominated landscapes which are generally very open, apart from scattered trees. Our results showed that without modelling movement between scattered trees (Fig. 3b), the leastcost paths were linear (and unnatural), with least-cost paths crossing vast cleared areas. The modelling also portrayed a more connected landscape, which overestimates overall connectivity as shown by the reduced number of components (Fig. 3b) and more linkages with high dIIC values (Fig. 4b). Models that fail to include scattered trees risk misrepresenting patterns of connectivity in agricultural landscapes such as the Karuah-Myall catchments.

The least-cost paths in Fig. 3b illustrated how dispersal patterns modelled without fine-scale connectivity bear little resemblance to what we would expect from the foray search strategy, commonly used by small- and medium-sized mammals and birds (Sun 1997; Koenig et al. 2000; Wiggett and Boag 2011) and regarded as being the preferred strategy for dispersal in fragmented landscapes (Conradt et al. 2003). Foray searchers would regularly return to their starting habitat to reorient and replenish themselves before gradually travelling further distances to reach new habitat (Conradt et al. 2001). Scattered trees and small patches can provide momentary respite in their search for new habitat. In a study on dispersal behaviour of woodland birds, both sedentary and nomadic bird species such as the Eastern Yellow Robin (Eopsaltria australis) and the White-plumed Honeyeaters (Lichenostomus penicillatus) were observed to use a foray search strategy for dispersal and moved between scattered trees not more than $80 \mathrm{~m}$ apart during their exploratory journeys (Doerr et al. 2011).

Aside from scattered trees, small and linear patches also contribute to connectivity within the study area, demonstrated by the high number of small patches with low $C C$ value patches across the landscape in the default scenario (Fig. 5a). A low CC value indicates that there are no alternative routes to these patches. In some cases, smaller patches can be the only pathway to an otherwise unreachable larger patch. It has been observed more broadly that conservation value decreases as patch size increases and the intactness of the surrounding landscape increases (Wintle et al. 2019). 


\section{Informing tree management policies in agricultural landscapes to support conservation}

The outcomes of our study are useful for informing scattered tree management by pinpointing key areas to focus on for tree conservation and regeneration efforts. Modelling with a gap crossing threshold effectively filters for trees that contribute to overall connectivity, and those that do not. Our modelling approach can demonstrate that scattered trees have significant value, which is not the case if conservation is purely focused on habitat area or threatened species. Tree recruitment practices can then be carried out in areas between isolated trees to close the gap and also to ensure that ageing trees are being replaced. Different grazing regimes and degrees of land use intensification can also influence the rate of tree regeneration within a pasture. Overgrazing reduces shade and shelter for seedlings (Bergmeier and Roellig 2014), and increased fertilization from land use intensification disrupts the soil nutrient balance that keeps mature trees healthy (Davidson et al. 2007). At the same time, grazing regimes such as a fast-rotational grazing (Longland 2013) can be proposed to enable farmers to remain economically productive and retain tree health and safeguard tree regeneration.

Of great concern for these degraded agricultural landscapes is that seed dispersal is highly reduced due to increasing fragmentation. Seed dispersal is a key ecological process that controls plant population and community persistence (Higgins et al. 2003; Pearson and Dawson 2005). Scattered trees contribute to the regeneration of these woody communities in degraded lands by acting as seedling nucleation foci (Slocum and Horvitz 2000; Zahawi and Augspurger 2006; Kelm et al. 2008), but their numbers are still in decline due to clearing, natural death and lack of regeneration (Gibbons et al. 2008). Fischer et al. (2009) reported that in their 800,000-ha study area of roughly 3 million scattered trees, the chance of regeneration was extremely low, due to conventional livestock grazing and fertilizer use. By extrapolation, they estimated that millions of hectares of southeastern Australia's grazing regions will become treeless if conventional management persists. On the other hand, tree recruitment practices often incur large costs as farmers would have to halt grazing temporarily (Kikoti et al. 2015) and set up tree guards (Baumber et al. 2017) until seedlings can withstand grazing.

\section{Priorities for catchment scale connectivity}

Our analyses indicate that scattered trees and small patches make important contributions to overall connectivity across and outside the study area. Many parts of the catchments which make important contributions to connectivity have no formal protection status. While the Karuah-Myall catchments appear to be well connected for a cleared pasture dominated agricutural landscape, east-west linkages across the cleared valley floors should be prioritised to preserve connectivity to ensure future connectivity. The analyses suggest that immediate priority focus areas for enhanced connectivity status or function exist at several areas, notably The Glen Nature Reserve west to Avon River State Forest (no protected status), the Karuah National Park northeast to Myall River State Forest (no protected status) and Karuah National Park to Monkerai Nature Reserve (contribution to Great Eastern Ranges Initiative).

The value of the study area for connectivity is not only for biodiversity within the three catchments but beyond the catchments as part of the GER. The Karuah catchment appears to also connect the coastal forested areas within the Myall Lakes catchment to patches in the GER. Critically, this connection is dependent on number of key patches and linkages in the north (Fig. 7a).

\section{Future research and limitations}

There are several areas which future research should target to build on the findings presented here. Firstly, we used a landscape feature approach to model for a "general representative species" to characterise general connectivity. This differs from a multi-species approach (Lechner et al. 2017). Additionally, scattered tree characteristics such as their height, age and canopy size were not considered in our analyses, which can be critical factors for tree use for many species (Dean et al. 1999; Gibbons and Lindenmayer 2002; Leonard Jr. and DeLotelle 2003). Future work could include a dispersal guild approach as an intermediate between single species models and land-facets approach, or a multi-scenario approach to model connectivity for different landscape conditions or species parameters. These options provide generalisability, while also targeting a specific group of species that have overlapping habitats or exploit the same resources (Lechner et al. 2017). Field data describing the composition of scattered tree species and floristic diversity would also complement the modelling presented here.

\section{Conclusion}

This study modelled connectivity for the Karuah-Myall catchments, a forest landscape fragmented by a matrix dominated by pasture agriculture. Our approach allowed for the importance of fine-scale features such as scattered trees to be quantified from the perspective of connectivity. For realistic fine-scale movement patterns to be characterised from an ecological perspective, scattered trees should be incorporated into spatial data and connectivity modelling. This will allow land managers to identify the important conservation values of these features which are often ignored. More specifically for our 
study area, the modelling showed that the Karuah-Myall catchments are well connected for a "generalised representative species", and that patches within the catchment may make an important contribution to connecting biodiversity beyond the geographical boundaries of the study area due to its location within the Great Eastern Range. However, connectivity even at large scales can potentially be influenced by the presence or absence of even the smallest features such as scattered trees.

\section{Abbreviations}

CC: Clustering coefficient; dIIC: Delta integral index of connectivity; GER: Great Eastern Ranges; IIC: Integral index of connectivity; NC: Number of components

\section{Acknowledgements}

Not applicable.

\section{Availability of data and material}

The data that support the findings of this study are available from MidCoast Council, but restrictions apply to the availability of these data, which were used under license for the current study, and so are not publicly available. Data are however available from the authors upon reasonable request and with permission of MidCoast Council.

\section{Authors' contributions}

This study was designed and coordinated by AL. DTCF performed the analysis of land cover data and synthesised the model inputs. AM and MB contributed land cover datasets. CG and BA provided conceptual and technical guidance for all aspects of the project. The manuscript was written by DTCF and commented on by all authors. All authors read and approved the final manuscript.

\section{Funding}

This research did not receive any specific grant from funding agencies in the public, commercial, or not-for-profit sectors.

\section{Ethics approval and consent to participate}

Not applicable.

\section{Consent for publication}

Not applicable.

\section{Competing interests}

The authors declare that they have no competing interests.

\begin{abstract}
Author details
${ }^{1}$ School of Environmental and Geographical Sciences, University of Nottingham Malaysia, Jalan Broga, 43500 Semenyih, Selangor, Malaysia. ${ }^{2}$ MidCoast Council, 2 Biripi Way, Taree, NSW 2430, Australia. ${ }^{3}$ Faculty of Forestry \& Environment, Universiti Putra Malaysia, 43400 Serdang, Selangor, Malaysia. ${ }^{4}$ Lincoln Centre for Water and Planetary Health, School of Geography, University of Lincoln, Lincoln LN6 7TS, UK.
\end{abstract}

Received: 16 September 2020 Accepted: 3 February 2021

Published online: 08 March 2021

\section{References}

Adriaensen F, Chardon JP, De Blust G et al (2003) The application of ' least-cost' modelling as a functional landscape model. Landsc Urban Plan 64:233-247 https://doi.org/10.1016/S0169-2046(02)00242-6

Barth BJ, FitzGibbon SI, Gillett A et al (2020) Scattered paddock trees and roadside vegetation can provide important habitat for koalas (Phascolarctos cinereus) in an agricultural landscape. Aust Mammal 42:194-203

Baumber A, Evans H, Turner RJ et al (2017) Enhancing seedling survival on former floodplain grazing land in the Capertee Valley, Australia. Ecol Manag Restor 18:253-256 https://doi.org/10.1111/emr.12273
Beier P, Spencer W, Baldwin RF, McRae BH (2011) Toward best practices for developing regional connectivity maps. Conserv Biol 25:879-892 https://doi. org/10.1111/j.1523-1739.2011.01716.x

Bélisle M, Desrochers A (2002) Gap-crossing decisions by forest birds: an empirical basis for parameterizing spatially-explicit, individual-based models. Landsc Ecol 17:219-231. https://doi.org/10.1023/A:1020260326889

Bergmeier E, Roellig M (2014) Diversity, threats and conservation of European wood-pastures. In: European wood-pastures in transition: A social-ecological approach. pp 19-38

Bolliger J, Silbernagel J (2020) Contribution of connectivity assessments to green infrastructure (GI). ISPRS Int J Geo-Inf 9:212 https://doi.org/10.3390/ijgi904 0212

Brook BW, Sodhi NS, Bradshaw CJA (2008) Synergies among extinction drivers under global change. Trends Ecol Evol 23:453-460 https://doi.org/10.1016/j. tree.2008.03.011

Brost BM, Beier P (2012) Comparing linkage designs based on land facets to linkage designs based on focal species. PLoS One 7:e48965

Carruthers S, Bickerton H, Carpenter G, et al (2004) A landscape approach to determine the ecological value of paddock trees. Summary Report Years 1 \& 2, Biodiversity Assessment Services, South Australian Department of Water, Land and Biodiversity Conservation. Adelaide

Caughley G (1994) Directions in conservation biology. J Anim Ecol 63:215-244

Conradt L, Roper TJ, Thomas CD (2001) Dispersal behaviour of individuals in metapopulations of two British butterflies. Oikos 95:416-424 https://doi.org/1 0.1034/j.1600-0706.2001.950306.x

Conradt L, Zollner P, Roper T et al (2003) Foray search: an effective systematic dispersal strategy in fragmented landscapes. Am Nat 161:905-915 https://doi. org/10.1086/375298

Creegan HP, Osborne PE (2005) Gap-crossing decisions of woodland songbirds in Scotland: an experimental approach. J Appl Ecol 42:678-687 https://doi.org/1 0.1111/j.1365-2664.2005.01057.x

Dale MRT, Fortin M-J (2010) From graphs to spatial graphs. Annu Rev Ecol Evol Syst 41:21-38 https://doi.org/10.1146/annurev-ecolsys-102209-144718

Davidson NJ, Close DC, Battaglia M et al (2007) Eucalypt health and agricultural land management within bushland remnants in the Midlands of Tasmania, Australia. Biol Conserv 139:439-446 https://doi.org/10.1016/j. biocon.2007.07.019

Dean WRJ, Milton SJ, Jeltsch F (1999) Large trees, fertile islands, and birds in arid savanna. J Arid Environ 41:61-78 https://doi.org/10.1006/jare.1998.0455

Leonard DL Jr, DeLotelle RS (2003) The red-cockaded woodpecker: surviving in a firemaintained ecosystem. Auk 120:1201-1205 https://doi.org/10.1093/auk/120.4.1201

Derroire G, Coe R, Healey JR (2016) Isolated trees as nuclei of regeneration in tropical pastures: testing the importance of niche-based and landscape factors. J Veg Sci 27:679-691 https://doi.org/10.1111/jvs.12404

Desrochers A, Hannon SJ (1997) Gap crossing decisions by forest songbirds during the post-fledging period. Conserv Biol 11:1204-1210

Doerr VAJ, Doerr ED, Davies MJ (2011) Dispersal behaviour of Brown Treecreepers predicts functional connectivity for several other woodland birds. Emu Austral Ornithol 111:71-83 https://doi.org/10.1071/MU09118

Doerr VAJ, Doerr ED, Davies MJ (2014) Does structural connectivity facilitate dispersal of native species in Australia's fragmented terrestrial landscapes? a systematic review protocol. Environ Evid 3:9 https://doi.org/10.1186/2047-23 82-3-9

Dorrough J, Moxham C (2005) Eucalypt establishment in agricultural landscapes and implications for landscape-scale restoration. Biol Conserv 123:55-66 https://doi.org/10.1016/j.biocon.2004.10.008

ESRI (2018) ArcMap

Fischer J, Lindenmayer DB (2002) The conservation value of paddock trees for birds in a variegated landscape in southern New South Wales. 1. Species composition and site occupancy patterns. Biodivers Conserv 11:807-832 https://doi.org/10.1023/A:1015371511169

Fischer J, Lindenmayer DB (2006) Habitat fragmentation and landscape change: an ecological and conservation Synthesis. Island Press, Washington DC

Fischer J, Stott J, Zerger A, et al (2009) Reversing a tree regeneration crisis in an endangered ecoregion. Proc Natl Acad Sci 106:10386-10391 https://doi.org/1 0.1073/pnas.0900110106

Foltête JC, Clauzel C, Vuidel G (2012) A software tool dedicated to the modelling of landscape networks. Environ Model Softw 38:316-327 https://doi.org/10.1 016/j.envsoft.2012.07.002

Gibbons P, Lindenmayer D (2002) Tree hollows and wild life conservation in Australia. CSIRO Publishing 
Gibbons P, Lindenmayer D, Fischer J, et al (2008) The future of scattered trees in agricultural landscapes. Conserv Biol 22:1309-1319. https://doi.org/10.1111/j. 1523-1739.2008.00997.x

Great Lakes Council (2014) Karuah catchment management plan—community and stakeholder forum Outcomes Report

Great Lakes Council (2015) Great Lakes Council 2015 Waterway and Catchment Report. Foster

Grubb TC, Doherty PF (1999) On home-range gap-crossing. Auk 116:618-628 https://doi.org/10.2307/4089323

Hadley AS, Betts MG (2009) Tropical deforestation alters hummingbird movement patterns. Biol Lett 5:207-210 https://doi.org/10.1098/rsbl.2008. 0691

Higgins SI, Lavorel S, Revilla E (2003) Estimating plant migration rates under habitat loss and fragmentation. Oikos 101:354-366 https://doi.org/10.1034/j.1 600-0706.2003.12141.x

Kelm D, Wiesner K, Helversen O (2008) Effects of artificial roosts for frugivorous bats on seed dispersal in a neotropical forest pasture mosaic. Conserv Biol 22:733-741 https://doi.org/10.1111/j.1523-1739.2008.00925.x

Kikoti I, Mligo C, Kilemo D (2015) The impact of grazing on plant natural regeneration in northern slopes of Mount Kilimanjaro, Tanzania. Open J Ecol 5:266-273 https://doi.org/10.4236/oje.2015.56021

Koenig WD, Hooge PN, Stanback MT, Haydock J (2000) Natal dispersal in the cooperatively breeding acorn woodpecker. Condor 102:492-502 https://doi. org/10.1093/condor/102.3.492

Le Roux DS, Ikin K, Lindenmayer DB et al (2018) The value of scattered trees for wildlife: Contrasting effects of landscape context and tree size. Divers Distrib 24:69-81 https://doi.org/10.1111/ddi.12658

Lechner AM, Brown G, Raymond CM (2015a) Modeling the impact of future development and public conservation orientation on landscape connectivity for conservation planning. Landsc Ecol 30:699-713 https://doi.org/10.1007/s1 0980-015-0153-0

Lechner AM, Doerr VAJ, Harris RMB et al (2015b) A framework for incorporating fine-scale dispersal behaviour into biodiversity conservation planning. Landsc Urban Plan 141:11-23 https://doi.org/10.1016/j.landurbplan.2015.04.008

Lechner AM, Harris RMB, Doerr VAJ et al (2015c) From static connectivity modelling to scenario-based planning at local and regional scales. J Nat Conserv 28:78-88 https://doi.org/10.1016/j.jnc.2015.09.003

Lechner AM, Lefroy EC (2014) General approach to planning connectivity from local scales to regional (GAP CLoSR). University of Tasmania, Hobart

Lechner AM, Sprod D, Carter O, Lefroy EC (2017) Characterising landscape connectivity for conservation planning using a dispersal guild approach. Landsc Ecol 32:99-113 https://doi.org/10.1007/s10980-016-0431-5

Lechner SA, Jones SD, Ferwerda JG (2009) Remote sensing of small and linear features: Quantifying the effects of patch size and length, grid position and detectability on land cover mapping. Remote Sens Environ 113:2194-2204 https://doi.org/10.1016/j.rse.2009.06.002

Lindsay DL, Barr KR, Lance RF, et al (2008) Habitat fragmentation and genetic diversity of an endangered, migratory songbird, the golden-cheeked warbler (Dendroica chrysoparia). Mol Ecol 17:2122-2133 https://doi.org/10.1111/j.13 65-294X.2008.03673.x

Liu W, Hughes AC, Bai Y et al (2020) Using landscape connectivity tools to identify conservation priorities in forested areas and potential restoration priorities in rubber plantation in Xishuangbanna, Southwest China. Landsc Ecol 35:389-402 https://doi.org/10.1007/s10980-019-00952-2

Longland AC (2013) 18 - Pastures and pasture management. In: Geor RJ, Harris PA, Coenen MBT-EA and CN (eds). Equine Applied and Clinical Nutrition: Health, Welfare and Performance. W.B. Saunders, pp 332-350

Lumsden LF, Bennett AF (2005) Scattered trees in rural landscapes: foraging habitat for insectivorous bats in south-eastern Australia. Biol Conserv 122: 205-222 https://doi.org/10.1016/j.biocon.2004.07.006

Manning AD, Fischer J, Lindenmayer DB (2006) Scattered trees are keystone structures-implications for conservation. Biol Conserv 132:311-321. https:// doi.org/https://doi.org/10.1016/j.biocon.2006.04.023

Manning AD, Gibbons P, Lindenmayer DB (2009) Scattered trees: a complementary strategy for facilitating adaptive responses to climate change in modified landscapes? J Appl Ecol 46:915-919 https://doi.org/10.1111/j.13 65-2664.2009.01657.x

McRae DBG, Keitt TH, Shah VB (2008) Using circuit theory to model connectivity in ecology, evolution, and conservation. Ecology 89:2712-2724

MidCoast Council (2018) MidCoast Council compiled fine-scale vegetation community mapping. MidCoast Council, NSW, Australia
Minor ES, Urban DL (2008) A graph-theory framework for evaluating landscape connectivity and conservation planning. Conserv Biol 22:297-307 https://doi. org/10.1111/j.1523-1739.2007.00871.x

Pascual-Hortal L, Saura S (2006) Comparison and development of new graphbased landscape connectivity indices: Towards the priorization of habitat patches and corridors for conservation. Landsc Ecol 21:959-967 https://doi. org/10.1007/s10980-006-0013-z

Pearson R, Dawson T (2005) Long-distance plant dispersal and habitat fragmentation: identifying conservation targets for spatial landscape planning under climate change. Biol Conserv 123:389-401. https://doi.org/1 0.1016/j.biocon.2004.12.006

Prevedello JA, Almeida-Gomes M, Lindenmayer DB (2018) The importance of scattered trees for biodiversity conservation: A global meta-analysis. J Appl Ecol 55:205-214 https://doi.org/10.1111/1365-2664.12943

Rail J-F, Darveau M, Desrochers A, Pettorelli J (1997) Territorial responses of boreal forest birds to habitat gaps. Condor 99:976-980 https://doi.org/10.23 $07 / 1370150$

Rayfield B, Fortin MJ, Fall A (2011) Connectivity for conservation: a framework to classify network measures. Ecology 92:847-858 https://doi.org/10.1890/09-2190.1

Ricotta C, Stanisci A, Avena G, Blasi C (2000) Quantifying the network connectivity of landscape mosaics: a graph-theoretical approach. Commun Ecol 1:89-94

Robertson O, Radford J (2009) Gap-crossing decisions of forest birds in a fragmented landscape. Austral Ecol 34:435-446 https://doi.org/10.1111/ j.1442-9993.2009.01945.x

Rogan JE, Lacher Jr. TE (2018) Impacts of habitat loss and fragmentation on terrestrial biodiversity. In: Earth Systems and Environmental Sciences. Elsevier

Saura S, Pascual-Hortal L (2007) A new habitat availability index to integrate connectivity in landscape conservation planning: Comparison with existing indices and application to a case study. Landsc Urban Plan 83:91-103 https://doi.org/10.1016/j.landurbplan.2007.03.005

Sawyer SC, Epps CW, Brashares JS (2011) Placing linkages among fragmented habitats: do least-cost models reflect how animals use landscapes? J Appl Ecol 48:668-678 https://doi.org/10.1111/j.1365-2664.2011.01970.x

Slocum MG, Horvitz CC (2000) Seed arrival under different genera of trees in a neotropical pasture. Plant Ecol 149:51-62. https://doi.org/10.1023/A: 1009892821864

Sun C (1997) Dispersal of young in red squirrels (Tamiasciurus hudsonicus). Am Midl Nat 138:252-259 https://doi.org/10.2307/2426818

Urban DL, Keitt T (2001) Landscape connectivity: a graph-theoretic perspective. Ecology 82:1205-1218 https://doi.org/10.2307/2679983

Urban DL, Minor ES, Treml EA, Schick RS (2009) Graph models of habitat mosaics. Ecol Lett 12:260-273 https://doi.org/10.1111/j.1461-0248.2008.01271.x

van der Ree R, Bennett AF, Gilmore DC (2004) Gap-crossing by gliding marsupials: thresholds for use of isolated woodland patches in an agricultural landscape. Biol Conserv 115:241-249 https://doi.org/10.1016/S0006-3207(03 )00142-3

Wiggett D, Boag D (2011) Intercolony natal dispersal in the Columbian ground squirrel. Can J Zool 67:42-50 https://doi.org/10.1139/z89-007

Wilson B (2008) Influence of scattered paddock trees on surface soil properties: a study of the Northern Tablelands of NSW. Ecol Manag Restor 3:211-219 https://doi.org/10.1046/j.1442-8903.2002.00115.x

Wintle BA, Kujala H, Whitehead A, et al (2019) Global synthesis of conservation studies reveals the importance of small habitat patches for biodiversity. Proc Natl Acad Sci 116:909-914. https://doi.org/10.1073/pnas.1813051115ss

Zahawi R, Augspurger C (2006) Tropical forest restoration: tree islands as recruitment foci in degraded lands of Honduras. Ecol Appl 16:464-478 https://doi.org/10.1890/1051-0761(2006)016[0464:TFRTIA]2.0.CO;2

\section{Publisher's Note}

Springer Nature remains neutral with regard to jurisdictional claims in published maps and institutional affiliations. 